DOI: 10.20472/IAC.2018.040.052

\author{
CHHABILAL SAPKOTA \\ Star Technology \& IT Consultant Pvt. Ltd, Nepal
}

\title{
NEPAL GOVERNMENT ROLE ON INFORMATION TECHNOLOGY
}

\begin{abstract}
:
The author believes that developing countries (DC), in particular Nepal, need to urgently develop a culturally appropriate national strategy if they wish information technology (IT) to have a positive impact on their overall socio-economic development. While countries like Singapore claim to have very successful national strategies, the long-term impact on the country's social development may have been over looked. Left unchecked the technological marketplace will impose a hard-to-reverse negative role on small countries like Nepal. This will make it increasingly difficult for Nepal to decide it is own long-term preferences for social and economic development. Put bluntly, these countries need to decide what they want from the global technology marketplace and then work out how they are going to achieve it. It is believed that hard technological determinism can only be countered by very real and well thought out national strategies. The paper argues that the national IT strategy will need to address the issues of resistance to change due to cultural, personal and infrastructure factors, be very culturally sensitive and, given the rate change of the technology, will need to be constructed as an evolving, and learning system. The first stage in the development of such a system is to design an appropriate forum for discussion, and a well-constituted and ongoing decision-making protocol. It seems appropriate that in countries with a less than thriving technology marketplace, it is incumbent on their Government to provide a lead in this complex undertaking.
\end{abstract}

\section{Keywords:}

Information Technology, Government Role, Nepal, Development 